\title{
LETTER
}

\section{Effect of impurities on cathodoluminescence of tridymite and cristobalite}

\author{
Masahiro KAYAMA ${ }^{*}$, Hirotsugu NISHIDO ${ }^{*}$ and Kiyotaka NinAGAWA ${ }^{* *}$ \\ ${ }^{*}$ Research Institute of Natural Sciences, Okayama University of Science, \\ 1-1 Ridaicho, Kita-ku, Okayama 700-005, Japan \\ ${ }^{* *}$ Department of Applied Physics, Okayama University of Science, \\ 1-1 Ridaicho, Kita-ku, Okayama 700-005, Japan
}

\begin{abstract}
Cristobalite and tridymite in andesite and obsidian exhibit bright blue emissions in color cathodoluminescence (CL) images. CL spectra of cristobalite and tridymite show emission bands at 400 and $430 \mathrm{~nm}$, respectively. Their CL intensity decreases with an increase in the electron irradiation time, similar to the short-lived blue luminescence reported in hydrothermal quartz. The reduction rate of the CL intensity of hydrothermal quartz is small as compared to cristobalite and tridymite. The initial CL intensity of both minerals immediately after the electron irradiation is positively correlated with the $\mathrm{Al}_{2} \mathrm{O}_{3}$ content. This suggests that the blue emissions of cristobalite and tridymite can be attributed to the $\left[\mathrm{AlO}_{4} / \mathrm{M}^{+}\right]^{0}$ defect center $\left(\mathrm{M}: \mathrm{H}^{+}, \mathrm{Li}^{+}, \mathrm{Na}^{+}\right.$, and $\left.\mathrm{K}^{+}\right)$. The electron irradiation of cristobalite and tridymite diffuses the monovalent cations of $\mathrm{H}^{+}, \mathrm{Li}^{+}$, and $\mathrm{Na}^{+}$and destroys their crystal structure, resulting in short-lived blue luminescence. The CL intensity after $600 \mathrm{~s}$ of electron irradiation depends on the $\mathrm{K}_{2} \mathrm{O}$ impurity content. In contrast to other monovalent cations, the $\mathrm{K}^{+}$cation is not diffused because of its large ionic radius. The CL emissions of cristobalite and tridymite after $600 \mathrm{~s}$ of electron irradiation can be attributed to the $\left[\mathrm{AlO}_{4} / \mathrm{M}^{+}\right]^{0} \operatorname{defect}\left(\mathrm{M}: \mathrm{K}^{+}\right)$. CL images of cristobalite in obsidian from Utah, USA, show a heterogeneous distribution of CL intensity, with oscillatory CL zoning on the rim and radial lath-shaped textures with bright CL superimposed on weak luminescence background. This implies that lath-shaped textures with bright emissions might have crystallized from rhyolitic magma at temperatures higher than the recrystallization temperature minerals in the other areas.
\end{abstract}

Keywords: Cathodoluminescence, Cristobalite, Tridymite, Short-lived luminescence

\section{INTRODUCTION}

Advanced applications of cathodoluminescence (CL) to silica minerals, especially quartz, have been extensively reported in geoscience literatures, e.g., for the interpretation of diagenesis and provenance (Owen, 1991; Götze et al., 2001; Goldstein and Rossi, 2002), observation of growth fabric microstructures (Boiron et al., 1992), investigation of radiation halo (Owen, 1988; Meunier et al., 1990; Komuro et al., 2002), and identification of silica minerals in meteorites (Chennaoui-Aoudjehane et al., 2005). Recently, Kayama et al. (2009) investigated the CL of tridymite and cristobalite to clarify the CL emission mechanism and luminescence centers in detail. They suggested that blue CL emissions of tridymite and cristobalite can be attributed to the $\left[\mathrm{AlO}_{4} / \mathrm{M}^{+}\right]^{0}$ defect $\left(\mathrm{M}^{+}: \mathrm{H}^{+}, \mathrm{Li}^{+}\right.$, $\mathrm{Na}^{+}$, and $\mathrm{K}^{+}$) associated with the $\mathrm{Al}^{3+}$ impurity substituting $\mathrm{Si}^{4+}$ in the $\mathrm{Si}-\mathrm{O}$ tetrahedra. The intensity of these doi:10.2465/jmps.090620a M. kayama,kayama@rins.ous.ac.jp Corresponding author emissions reduce during electron irradiation, where the monovalent cations $\left(\mathrm{H}^{+}, \mathrm{Li}^{+}\right.$, and $\left.\mathrm{Na}^{+}\right)$captured by the defects are easily diffused in the lattice. This CL behavior, i.e., short-lived blue luminescence, has been also reported in a previous CL study on hydrothermal quartz (Zinkernagel, 1978; Ramseyer et al., 1988; Ramseyer and Mullis, 1990; Perny et al., 1992). Raman spectroscopy revealed that the partial structural destruction of cristobalite and tridymite by electron bombardment promoted the diffusion of monovalent cations, resulting in short-lived luminescence (Kayama, et al., 2009). Kayama et al. (2009) also suggested that the impurity concentrations of aluminum and monovalent cations might be related to the reduction process of the CL intensity of both minerals; however, there is no quantitative evidence supporting such a scheme.

In this study, the CL of tridymite and cristobalite from various localities is examined to verify the effect of concentrations of impurities such as $\mathrm{Al}_{2} \mathrm{O}_{3}$ and $\mathrm{K}_{2} \mathrm{O}$ on the reduction process of $\mathrm{CL}$ intensity. Furthermore, $\mathrm{CL}$ mi- 
Table 1. Samples for CL measurements and their impurity contents

\begin{tabular}{llllcc}
\hline Mineral & No. & \multicolumn{1}{c}{ Locality } & \multicolumn{1}{c}{ Mode of occurrence } & $\mathrm{Al}_{2} \mathrm{O}_{3}(\mathrm{wt} \%)$ & $\mathrm{K}_{2} \mathrm{O}(\mathrm{wt} \%)$ \\
\hline Cristobalite & $\mathrm{C} 01$ & Coso Peak, USA & Small spherules crystals in obsidian & 0.34 & 0.02 \\
& $\mathrm{C} 03$ & Shizuoka, Japan & Small spherules crystals in andesite & 1.41 & 0.02 \\
& $\mathrm{C} 05$ & Kagoshima, Japan & Small spherules crystals in andesite & 0.75 & 0.01 \\
& $\mathrm{C} 11$ & California, USA & Small spherules crystals in obsidian & 0.88 & 0.03 \\
& C-Ob & Utah, USA & Small spherules crystals in obsidian & 0.76 & 0.11 \\
Tridymite & T01 & Vechec, Slovakia & Small tabular crystals in andesite & 1.12 & 0.27 \\
& T03 & Gunma, Japan & Small tabular crystals in andesite & 0.98 & 0.24 \\
& T07 & Kumamoto, Japan & Small tabular crystals in andesite & 1.02 & 0.25 \\
\hline
\end{tabular}

croscopy of cristobalite in obsidian is carried out to determine the relationship between the characteristic CL textures and the impurity content.

\section{SAMPLES AND METHODS}

Tridymite and cristobalite in andesite and obsidian from various localities were employed for CL spectral measurements (Table 1). Tridymite from Vechec, Gunma, and Kumamoto and cristobalite from Shizuoka and Kagoshima used in a previous study (Kayama et al., 2009) were considered as reference samples and their $\mathrm{CL}$ data were compared with the CL data of cristobalite from Coso Peak, California, and Utah. Hand-picked crystals were embedded in a small dimple $(\varphi: 2 \mathrm{~mm})$ on a brass disk using a nonluminescent epoxy resin and were polished and mirror-finished using diamond powder with particle size of $1 \mu \mathrm{m}$. The prepared samples were coated with a carbon film, $\sim 2 \mathrm{~nm}$ thick, to prevent charge build-up on the surface during electron irradiation. Polished thin sections of cristobalite $(\mathrm{C} 01, \mathrm{C} 11$, and $\mathrm{C}-\mathrm{Ob})$ occurring as small spherules in obsidian were also examined to characterize their CL textures by CL imaging.

Color CL images were obtained using a cold-cathode microscope (luminoscope), which consisted of an optical microscope, an electron gun, and a cooled charge-coupled device (CCD) camera. The instrument was operated at an accelerating voltage of $15 \mathrm{kV}$ and a beam current of 0.5 $\mathrm{mA}$ with $360-\mathrm{s}$ exposure. A scanning electron microscopy-cathodoluminescence (SEM-CL) analysis was carried out using an SEM (JEOL: JSM-5410) combined with a grating monochromator (Oxford: Mono CL2) to measure CL spectra ranging from $300 \mathrm{~nm}$ to $800 \mathrm{~nm}$ in 1-nm steps. All CL spectra were corrected for total instrumental response, which was determined using a calibrated standard lamp. This correction prevents errors in the peak position of emission bands and allows the quantitative evaluation of CL intensity. To prevent electron irradiation damage and a high $\mathrm{S} / \mathrm{N}$ ratio of CL signals, CL spectra should be measured at low current intensity. In this study, CL emissions of cristobalite $(\mathrm{C}-\mathrm{Ob})$ are found to be quite bright as compared to other samples. Hence, a low beam current has to be maintained to prevent the saturation of the photomultiplier detector. Therefore, CL spectral measurements on all tridymite and cristobalite samples are performed in the scanning mode across an area of $220 \mu \mathrm{m} \times 165 \mu \mathrm{m}$ at an accelerating voltage of $15 \mathrm{kV}$ and a beam current of 0.1 $\mathrm{nA}$; these conditions are different from those used in our previous study (Kayama et al., 2009). The change in the CL intensity at the peak positions with an increase in electron irradiation time is also monitored under a low current intensity of $1.0 \mathrm{nA}$ in the focused mode $(\varphi: 1 \mu \mathrm{m})$ for 600 s. Panchromatic CL images are obtained at high magnification using a CL detector (Gatan: MiniCL) that can be used for SEM-CL analysis; the spectral response of this detector has a maximum in the blue region and gradually decreases with an increase in the wavelength up to 800 $\mathrm{nm}$. The equipment construction and the analytical procedure are strictly followed from the reports of Ikenaga et al. (2000) and Kayama et al. (2009). Electron microprobe analysis was carried out to determine impurity contents in all samples using JEOL: JXA-8900R.

\section{RESULT}

All the cristobalite and tridymite samples exhibit bright blue emissions in the color CL images obtained using the luminoscope. Blue emissions of cristobalite and tridymite, however, diminish during electron irradiation. Every sample exhibits bright $\mathrm{CL}$ emissions in the initial period of electron irradiation. However, prolonged irradiation causes a progressive decrease in their CL intensity, and CL emissions become almost invisible to the naked eye after $1 \mathrm{~h}$ of irradiation.

The CL images obtained using the MiniCL imaging system show a homogeneous distribution of emission intensity, except for cristobalite in obsidian (C01, C11, and $\mathrm{C}-\mathrm{Ob}$ ). $\mathrm{C} 01$ and $\mathrm{C} 11$ exhibit oscillatory CL zoning, which shows bright areas on the rim and dull ones in the core. $\mathrm{C}-\mathrm{Ob}$ shows radial and lath-shaped textures (area B) with bright CL superimposed on weak luminescence background (area C) as well as oscillatory CL zoning (area A) (Figs. 1c and 1d). No features corresponding to such CL textures can be found in optical microscopic and back- 


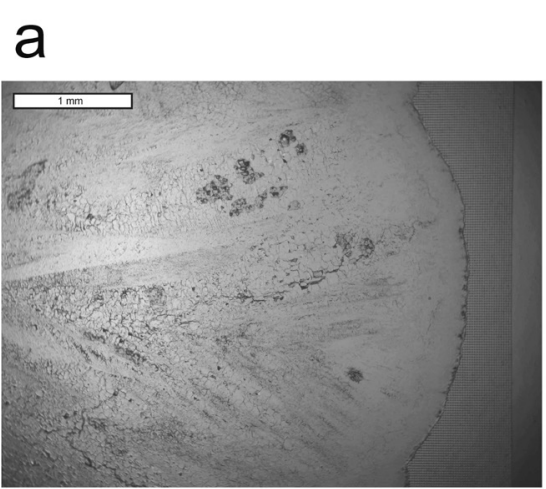

\section{C}

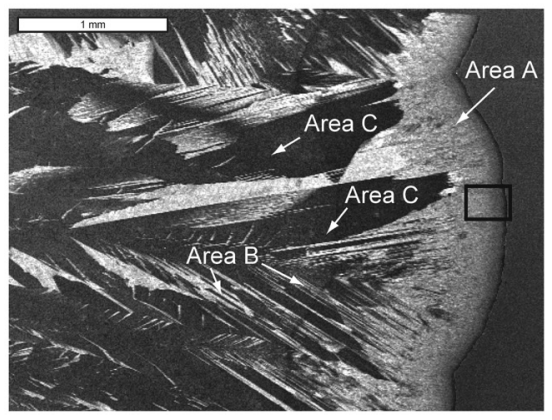

b

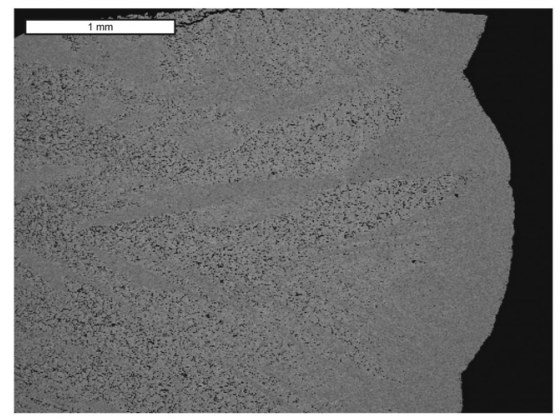

d



Figure 1. Cristobalite in obsidian $\left(\mathrm{C}^{-}\right.$ $\mathrm{Ob}$ ). (a) Optical microphotograph (parallel nicol). (b) BSE image. (c) CL image. (d) CL image at high magnification.

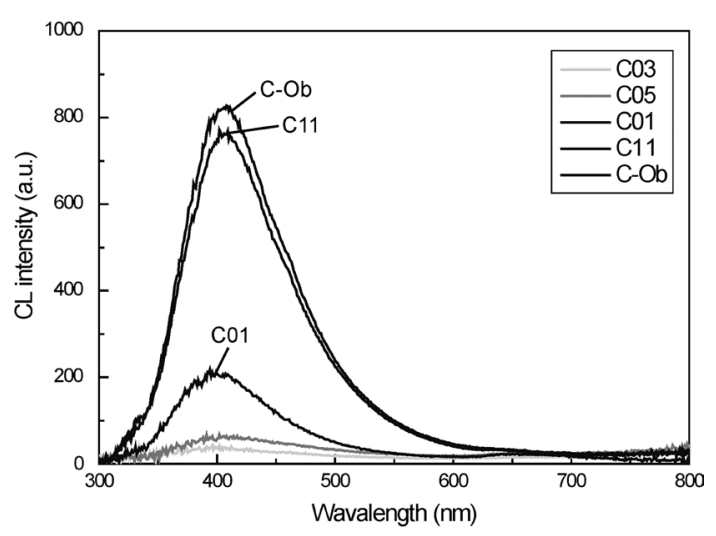

Figure 2. CL spectra of cristobalite in andesite and obsidian.

scatter electron (BSE) images (Figs. 1a and 1b).

CL spectroscopy in the scanning mode across an area of $220 \mu \mathrm{m} \times 165 \mu \mathrm{m}$ reveals that all cristobalite samples show an emission band at around $400 \mathrm{~nm}$ in the blue region (Fig. 2). The CL intensity of cristobalite from obsidian is higher than that of andesite. Additionally, CL spectra of $\mathrm{C} 01, \mathrm{C} 03$, and $\mathrm{C} 05$ show an emission band at around $650 \mathrm{~nm}$ with weak intensity. All tridymite samples show a CL spectral pattern with an emission band at around $430 \mathrm{~nm}$ in the blue region and at around $650 \mathrm{~nm}$ in the red region; the intensity of their red emissions are considerably lower than that of the blue ones (Fig. 3). The CL intensity of blue emissions of tridymite is higher than that of cristobalite in andesite. The integrated CL intensity

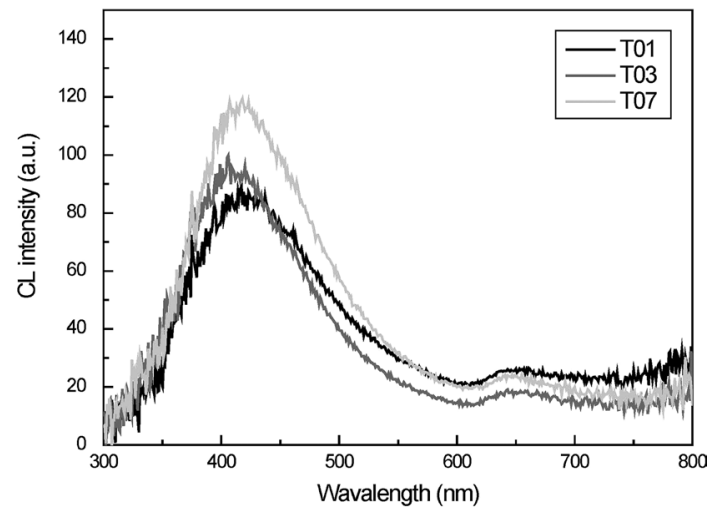

Figure 3. CL spectra of tridymite in andesite.

of the blue emission of both minerals is more than four times that of hydrothermal quartz from Poona, Maharashtra, India, whose CL spectra show a peak wavelength in the blue region at $390 \mathrm{~nm}$.

Electron irradiation causes a rapid decay of blue emissions of cristobalite and tridymite. The changes in $\mathrm{CL}$ intensities at the peak positions for all the cristobalite and tridymite samples are monitored during electron irradiation at $1.0 \mathrm{nA}$ in the focused mode for $600 \mathrm{~s}$ (Figs. 4 and 5). CL intensities of all samples decrease with an increase in the irradiation time, which is the characteristic behavior of short-lived luminescence. In all samples, the CL intensity abruptly dropped immediately after electron irradiation and then gradually decreased up to $600 \mathrm{~s}$. The 


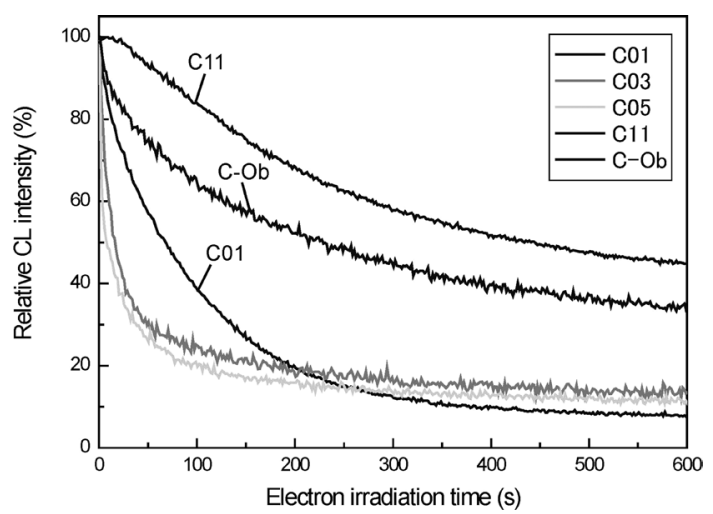

Figure 4. Decrease in CL intensity of cristobalite in blue region after electron irradiation at $15-\mathrm{kV}$ accelerating voltage and $1.0-\mathrm{nA}$ beam current in focused mode $(\varphi: 1 \mu \mathrm{m})$ for $600 \mathrm{~s}$.

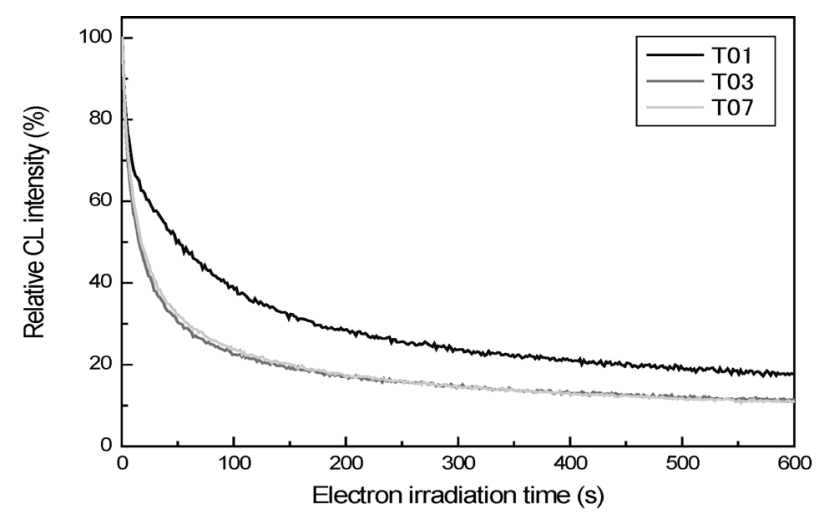

Figure 5. Decrease in CL intensity of tridymite in blue region after electron irradiation at $15-\mathrm{kV}$ accelerating voltage and $1.0-\mathrm{nA}$ beam current in focused mode $(\varphi: 1 \mu \mathrm{m})$ for $600 \mathrm{~s}$.

CL intensity reduction rate with respect to the electron irradiation time, however, is different for the samples. After $100 \mathrm{~s}$ of electron irradiation, the CL intensity at the peak maximum becomes $22 \%-38 \%$ of the initial intensity for tridymite (T01, T03, and $\mathrm{T} 07)$ and cristobalite (C03 and $\mathrm{C} 05)$ in andesite, whereas a small change in the reduction rate of CL intensity is observed during electron irradiation from $100 \mathrm{~s}$ up to $600 \mathrm{~s}$, where the minima of the reduction rate reached $11 \%-17 \%$ after $600 \mathrm{~s}$ of irradiation (Figs. 4 and 5). During 100-s irradiation, the CL intensity of cristobalite in obsidian, i.e., $\mathrm{C} 01, \mathrm{C} 11$, and $\mathrm{C}-\mathrm{Ob}$, however, decreases down to $38 \%, 84 \%$, and $63 \%$ of the initial intensity, respectively (Fig. 4). After prolonged irradiation for $600 \mathrm{~s}$, their intensity reduces to approximately $8 \%$, $45 \%$, and $35 \%$ of the initial intensity, respectively.

\section{DISCUSSION}

The measured CL spectra of cristobalite and tridymite show emission bands at around 400 and $430 \mathrm{~nm}$, respec-

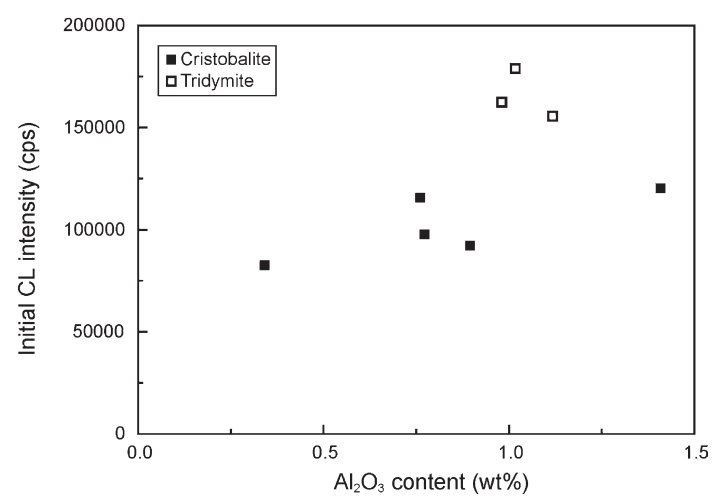

Figure 6. Plot of initial intensity of blue emission immediately after electron irradiation against $\mathrm{Al}_{2} \mathrm{O}_{3}$ content.

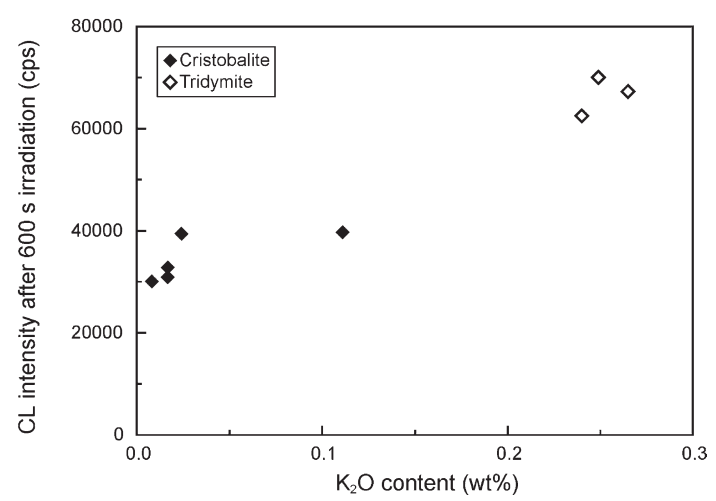

Figure 7. Plot of initial intensity of blue emission after electron irradiation for $600 \mathrm{~s}$ against $\mathrm{K}_{2} \mathrm{O}$ content.

tively (Figs. 2 and 3). Both minerals show a drop in the $\mathrm{CL}$ intensity in the blue region immediately after electron irradiation and a subsequent gradual decrease in the CL intensity during irradiation up to $600 \mathrm{~s}$ (Figs. 4 and 5); this CL behavior observed in previous CL studies on cristobalite, tridymite, and quartz has been reported as shortlived blue luminescence related to the $\left[\mathrm{AlO}_{4} / \mathrm{M}^{+}\right]^{0}$ defect $\left(\mathrm{M}^{+}: \mathrm{H}^{+}, \mathrm{Li}^{+}\right.$, and $\left.\mathrm{Na}^{+}\right)$(Zinkernagel, 1978; Ramseyer et al., 1988; Ramseyer and Mullis, 1990; Perny et al., 1992; Kayama et al., 2009). All of the analyzed tridymite and cristobalite samples exhibit short-lived blue luminescence. However, the reduction rates of their CL intensity in the blue region during electron irradiation are quite different. This can be correlated to the impurity content of $\mathrm{Al}_{2} \mathrm{O}_{3}$ and $\mathrm{K}_{2} \mathrm{O}$ (Figs. 6 and 7). The $\mathrm{Al}_{2} \mathrm{O}_{3}$ and $\mathrm{K}_{2} \mathrm{O}$ contents in the samples are found to be $0.34-1.41 \mathrm{wt} \%$ and $0.01-0.27 \mathrm{wt} \%$, respectively, by electron microprobe analysis. The $\mathrm{Al}$ concentration in cristobalite in obsidian is lower than that in cristobalite and tridymite in andesite. The initial CL intensity of cristobalite and tridymite immediately after electron irradiation is positively correlated to the $\mathrm{Al}$ impurity content (Fig. 6). The CL intensity of 
quartz in the blue region also shows such a positive correlation with the $\mathrm{Al}$ content and the $\mathrm{Li}^{+}$and $\mathrm{Na}^{+}$contents (Ramseyer and Mullis, 1990; Perny et al., 1992). Therefore, blue emissions of quartz can be attributed to the $\left[\mathrm{AlO}_{4} / \mathrm{M}^{+}\right]^{0}$ defect center $\left(\mathrm{M}: \mathrm{Li}^{+}\right.$and $\left.\mathrm{Na}^{+}\right)$. Similarly, the short-lived blue luminescence observed in cristobalite and tridymite can be attributed to the $\left[\mathrm{AlO}_{4} / \mathrm{M}^{+}\right]^{0}$ defect center $\left(\mathrm{M}: \mathrm{H}^{+}, \mathrm{Li}^{+}\right.$and $\left.\mathrm{Na}^{+}\right)$. The CL intensity after $600 \mathrm{~s}$ of electron irradiation depends on the $\mathrm{K}_{2} \mathrm{O}$ impurity content (Fig. 7). The $\mathrm{CL}$ intensity of tridymite $\left(\mathrm{K}_{2} \mathrm{O}\right.$ content: $0.24-0.27 \mathrm{wt} \%)$ is higher than that of cristobalite $\left(\mathrm{K}_{2} \mathrm{O}\right.$ content: $0.01-0.11 \mathrm{wt} \%)$. This indicates that the CL emissions observed after prolonged electron irradiation can be attributed to the $\left[\mathrm{AlO}_{4} / \mathrm{M}^{+}\right]^{0}$ defect $\left(\mathrm{M}: \mathrm{K}^{+}\right)$. In contrast to other monovalent cations, the $\mathrm{K}^{+}$cation is not diffused by electron irradiation due to its large ionic radius, on the basis of diffusion behavior of the cations $\left(\mathrm{H}^{+}, \mathrm{Li}^{+}, \mathrm{Na}^{+}\right.$and $\mathrm{K}^{+}$) at room temperature in quartz (Sibley et al., 1979; Halliburton et al., 1981; Bahadur, 1994). The decrease in the CL intensity of both minerals during electron irradia-


and/or $\mathrm{Na}^{+}$), where these monovalent cations are easily diffused by electron irradiation even when exposed for a short period. Furthermore, cristobalite and tridymite in andesite exhibit an abrupt drop in the CL intensity immediately after electron irradiation up to $100 \mathrm{~s}$ as compared to cristobalite in obsidian (Figs. 4 and 5). After $100 \mathrm{~s}$ of electron irradiation, the CL intensity at the peak maximum becomes $22 \%-38 \%$ of the initial intensity for tridymite (T01, T03, and T07) and cristobalite ( $\mathrm{C} 03$ and $\mathrm{C} 05)$ in andesite and $38 \%-84 \%$ of the initial intensity for cristobalite in obsidian $(\mathrm{C} 01, \mathrm{C} 11$, and $\mathrm{C}-\mathrm{Ob})$. After the abrupt drop, the CL intensity decreases gradually up $600 \mathrm{~s}$, reaching $11 \%-17 \%$ of the initial intensity for cristobalite and tridymite in andesite and $8 \%-45 \%$ of the initial intensity for cristobalite in obsidian. These results imply that monovalent cations such as $\mathrm{H}^{+}, \mathrm{Li}^{+}$, and $\mathrm{Na}^{+}$are almost completely diffused on cristobalite and tridymite in andesite during electron irradiation for 100-600 s, but are only partly diffused on cristobalite in obsidian under this beam condition.

Oscillatory zoning with bright areas on the rim and dull ones in the core is observed in CL images of cristobalite in obsidian. However, no such features are observed in CL images of cristobalite in andesite. CL images of $\mathrm{C} 01$ and $\mathrm{C} 11$ show oscillatory $\mathrm{CL}$ zoning in which a bright rim corresponding to cristobalite and a dull core corresponding to amorphous silica minerals, identified by Raman spectroscopy, are observed. Amorphous silica minerals exhibit dark CL emissions, which are not observed in crystalline minerals (Stevens-Kalceff et al., 2000). This suggests that CL microscopy can be used to identify amorphous and crystalline silica minerals and visualize their spatial distributions. A CL image of $\mathrm{C}-\mathrm{Ob}$ shows the characteristic distribution of CL intensity, which is not observed in the other cristobalite samples. It shows oscillatory CL zoning on the rim (area A) and radial lath-shaped textures (area B) with bright CL superimposed on weak luminescence background (area C) (Figs. 1c and 1d). Raman spectroscopy proves the absence of other minerals such as quartz, tridymite, and amorphous $\mathrm{SiO}_{2}$ in this area. No features corresponding to oscillatory zoning and lath-shaped CL textures are observed in optical microscopic and BSE images (Figs. 1a and 1b). The difference between the $\mathrm{CL}$ intensities of these $\mathrm{CL}$ textures might be related to the $\mathrm{Al}_{2} \mathrm{O}_{3}$ and $\mathrm{K}_{2} \mathrm{O}$ contents. Bright lath-shaped areas have a high concentration of $\mathrm{K}_{2} \mathrm{O}$ and $\mathrm{Al}_{2} \mathrm{O}_{3}$ impurity, 0.02 and $0.90 \mathrm{wt} \%$, respectively; the $\mathrm{K}_{2} \mathrm{O}$ and $\mathrm{Al}_{2} \mathrm{O}_{3}$ contents in the dark areas are at the most 0.11 and $0.76 \mathrm{wt} \%$, respectively. According to Dennen et al. (1970), the ratio of Al between an aluminous phase and quartz can be used to determine the temperature of crystallization, because the $\mathrm{Al}$ content in quartz is linearly correlated to the temperature. This implies that the lathshaped areas with bright emissions might have crystallized from rhyolitic magma at higher temperature than other dark areas. Thus, CL spectroscopy and microscopy provide detailed information on the thermal history during the crystallization of cristobalite, which is quite difficult to obtain using other analytical methods.

\section{ACKNOWLEDGMENTS}

We are deeply indebted to late H. Bahadur (NPL-INDIA) for the valuable information on electron irradiation effects and for his useful discussions throughout this study, T. Okumura (Okayama University of Science) for the useful information on CL of quartz, and C. Gouzu (Hiruzen Institute for Geology \& Chronology) for his technical support during the electron microprobe analysis.

\section{REFERENCES}

Bahadur, H. (1994) Low-temperature irradiation effects in natural crystalline quartz. Journal of Applied Physics, 75, 14201425.

Boiron, M.C., Essarraj, S., Sellier, E., Cathelineau, M., Lespinasse, M. and Poty, B. (1992) Identification of fluid inclusions in relation to their host microstructural domains in quartz by cathodoluminescence. Geochimica et Cosmochimica Acta, 56, 175-185.

Chennaoui-Aoudjehane, H., Jambon, A., Reynard, B. and Blanc, P. (2005) Silica as a shock index in shergottites: A cathodoluminescence study. Meteoritics and Planetary Science, 40, Nr 7, 967-979.

Dennen, W.H., Blackburn, W.H. and Queseda, A. (1970) Alumi- 
num in quartz as a geothermometer. Contributions to Mineralogy and Petrology, 27, 332-342.

Goldstein, R.H. and Rossi, C. (2002) Recrystallization in quartz overgrowths. Journal of Sedimentary Research, 72, 432-440.

Götze, J., Plötze, M. and Habermann, D. (2001) Origin, spectral characteristics and practical applications of the cathodoluminescence (CL) of quartz - a review, Mineralogy and Petrology, 71, 225-250.

Halliburton, L.E., Koumvakalis, N., Markes, M.E. and Martin, J.J. (1981) Radiation effects in crystalline $\mathrm{SiO}_{2}$ : The role of aluminum. Journal of Applied Physics, 52, 3565-3574.

Ikenaga, M., Nishido, H. and Ninagawa, K. (2000) Performance and analytical conditions of cathodoluminescence scanning electron microscope (CL-SEM). The Bulletin of Research Institute of Natural Sciences Okayama University of Science, 26, 61-75.

Kayama, M., Nishido, H. and Ninagawa, K. (2009) Cathodoluminescence characterization of tridymite and cristobalite: Effects of electron irradiation and sample temperature, American Mineralogist, 94, 1018-1028.

Komuro, K., Horikawa, Y. and Toyoda, S. (2002) Development of radiation-damage halos in low-quartz: cathodoluminescence measurement after $\mathrm{He}^{+}$ion implantation, Mineralogy and Petrology, 76, 261-266.

Meunier, J.D., Sellier, E. and Pagel, M. (1990) Radiation-damage rims in quartz from uranium-bearing sandstones. Journal of Sedimentary Research, 60, 53-58.

Owen, M.R. (1988) Radiation-damage halos in quartz. Geology, $16,529-532$.

Owen, M.R. (1991) Application of cathodoluminescence to sand- stone provenance. In Luminescence microscopy: quantitative and qualitative aspects (Barker, C.E., Kopp, O. C. Eds.). SEPM Dallas/Texas, 25, Tulsa, 67-76.

Perny, B., Eberhardt, P., Ramseyer, K., Mullis, J. and Pankrath, R. (1992) Microdistribution of $\mathrm{Al}, \mathrm{Li}$, and $\mathrm{Na}$ in $\alpha$-quartz: Possible causes and correlation with short-lived cathodoluminescence. American Mineralogist, 77, 534-544.

Ramseyer, K. and Mullis, J. (1990) Factors influencing short-lived blue cathodoluminescence of $\alpha$-quartz. American Mineralogist, 75, 791-800.

Ramseyer, K., Baumann, J., Matter. A. and Mullis, J. (1988) Cathodoluminescence colors of $\alpha$-quartz. Mineralogical Magazine, 52, 669-677.

Stevens-Kalceff, M.A., Matthew, R.P, Anthony, R.M. and Kalceff, W. (2000) Cathodoluminescence Microcharacterisation of Silicon Dioxide Polymorphs. In Cathodoluminescence in Geosciences (Pagel, M., Barbin, V., Blanc, P. and Ohnenstetter. D. Eds.). Springer-Verla, Berlin, 193-223.

Sibley, W.A., Martin, J.J., Wintersgill, M.C. and Brown, J.D. (1979) The effect of radiation on the $\mathrm{OH}$ - infrared absorption of quartz crystals. Journal of Applied Physics, 50, 54495452.

Zinkernagel, U. (1978) Cathodoluminescence of quartz and its application to sandstone petrology. Contributions to Sedimentology, 8, 69 .

Manuscript received June 20, 2009

Manuscript accepted October 12, 2009

Published online November 26, 2009

Manuscript handled by Koichiro Fujimoto 